\title{
Sesame-like Pigmentation in the Duodenum
}

\author{
Jung Bin Yoon ${ }^{1}$, Gwang Ha Kim ${ }^{1,2}$ \\ Department of Internal Medicine, Pusan National University School of Medicine ${ }^{1}$, Biomedical Research Institute, Pusan National University \\ Hospital $^{2}$, Busan, Korea
}

Question: A 56-year-old woman visited our hospital for endoscopic treatment of a $1.5-\mathrm{cm}$ early gastric cancer in the gastric antrum. She had diabetes mellitus and hypertension, and had taken iron supplementation for 3 years because of iron deficiency anemia. On upper endoscopy, diffuse sesame-like dark brown pigmentation was found in the bulb and second portion of the duodenum (Fig. 1A). On magnifying endoscopy with narrow-band imaging, the sesame-like pigmentation was confined to the duodenal villi.

What is the most likely diagnosis?

Answer: Histopathologically, an endoscopic biopsy specimen from the duodenal bulb revealed hemosiderin-laden macrophages in the lamina propria within the normal structure of duodenal villi (Fig. 2). A diagnosis of pseudomelanosis duodeni was made based on the endoscopic and histopathological findings. The patient underwent endoscopic submucosal dissection for early gastric cancer and has been followed up without recurrence.

Pseudomelanosis duodeni is a rare entity characterized by dark pigmented granules (including ferrous sulfide with small amounts of other elements) seen inside the macrophages that lie within the lamina propria of the duodenal villi. ${ }^{1}$ Although no clear etiology has been described, there are several proposed mechanisms regarding pathogenesis, including impaired luminal transport of iron or intramucosal hemorrhage in patients with hypertension, chronic renal failure, chronic heart failure and diabetes mellitus. ${ }^{2}$ In addition, certain drugs, including oral iron, hydralazine, propranolol, hydrochlorothiazide and furosemide, have also been associated with pseudomelanosis
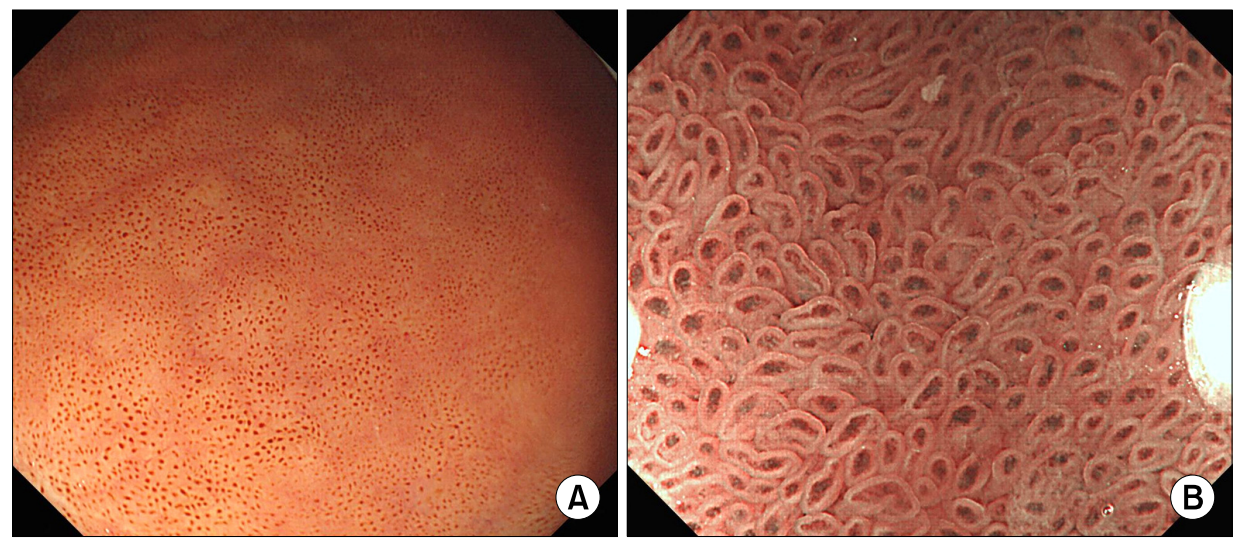

Fig. 1. (A) Esophagogastroduodenoscopy reveals diffuse sesame-like dark brown pigmentation in the duodenal bulb. (B) On magnifying endoscopy with narrow-band imaging, sesamelike pigmentation is confined to the duodenal villi.

Received: April 17, 2017 Revised: April 28, 2017 Accepted: May 1, 2017

Corresponding author: Gwang Ha Kim

Department of Internal Medicine, Pusan National University School of Medicine, and Biomedical Research Institute, Pusan National University Hospital, 179 Gudeok-ro, Seo-gu, Busan 49241, Korea

Tel: +82-51-240-7869, Fax: +82-51-244-8180, E-mail: doc0224@pusan.ac.kr

Copyright $\odot 2017$ Korean College of Helicobacter and Upper Gastrointestinal Research

() The Korean Journal of Helicobacter and Upper Gastrointestinal Research is an Open-Access Journal. All articles are distributed under the terms of the Creative Commons Attribution Non-Commercial License (http://creativecommons.org/licenses/by-nc/4.0) which permits unrestricted non-commercial use, distribution, and reproduction in any medium, provided the original work is properly cited. 


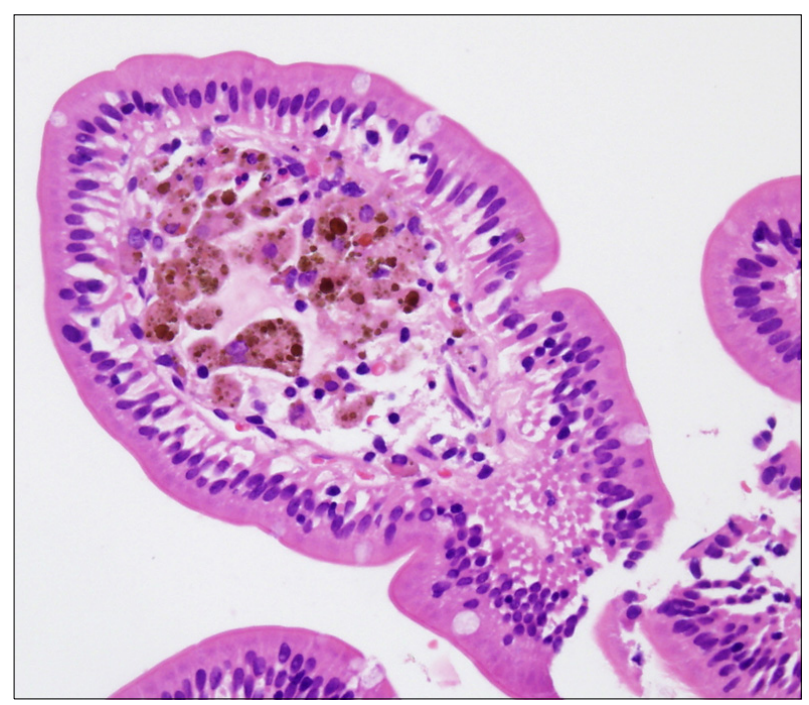

Fig. 2. Histopathologically, hemosiderin-laden macrophages are seen in the lamina propria within the normal structure of duodenal villi (H\&E, $\times 400)$. duodeni. ${ }^{2}$ There is no known treatment, and no specific follow-up protocols have been outlined so far. ${ }^{3}$ Pseudomelanosis duodeni, per se, does not lead to any clinical symptoms or adverse consequences; however, the peculiar endoscopic features is unusual and may pose an initial diagnostic challenge to endoscopists who are unaware of this condition.

\section{REFERENCES}

1. Giusto D, Jakate S. Pseudomelanosis duodeni: associated with multiple clinical conditions and unpredictable iron stainabilitya case series. Endoscopy 2008;40:165-167.

2. Kim SY, Choung RS, Kwon BS, et al. Small bowel pseudomelanosis associated with oral iron therapy. J Korean Med Sci 2013;28:1103-1106.

3. Kakati B, Krishna S, Sharma S, Rego R. Pseudomelanosis duodeni: a rare finding from upper endoscopy. Dig Endosc 2011;23:201-202. 